\title{
INFLUENCE OF INITIAL TEXTURE, TEMPERATURE AND TOTAL STRAIN ON THE TEXTURE DEVELOPMENT OF POLYCRYSTALLINE PYRRHOTITE ORES IN DEFORMATION EXPERIMENTS
}

\author{
ELKE NIEDERSCHLAG ${ }^{1)}$ and HEINRICH SIEMES ${ }^{2)}$ \\ ${ }^{1)}$ Mühlstraße 22, D-01454 Radeberg (Germany) \\ ${ }^{2)}$ Institut für Mineralogie und Lagerstättenlehre, RWTH Aachen, Wüllnerstraße 2, \\ D-52056 Aachen (Germany)
}

(Received 17 May 1996)

\begin{abstract}
The development of the crystallographic preferred orientation (texture) of polycrystalline pyrrhotite from Sullivan mine, Canada, and Cerro de Pasco, Peru was determined by neutron texture analyses before and after experimental deformation. The pyrrhotite ore from Sullivan has an initial texture with a distinct c-axis maximum perpendicular to the foliation whereas the ore from Cerro de Pasco shows a weak and moreover inhomogeneous texture within the specimen.

The deformation texture and deformation behaviour of samples from Sullivan were investigated as a function of temperature, total strain and the angle between the compression axis and the initial caxis maximum. The deformation textures show the influence of different activated glide modes ${ }^{1}$ as a function of the compression direction and temperature. Investigations of the deformation texture and deformation behaviour of samples from Cerro de Pasco were carried out as a function of temperature, total strain and strain rate. The inhomogeneous texture of the starting material did not allow to draw conclusions about the texture development as a function of strain rate and temperature. Nevertheless the preferred orientation of the c-axes parallel to the compression axis becomes more evident with increasing total strain.
\end{abstract}

KEY WORDS: Pyrrhotite, neutron texture analysis, experimental deformation, deformation texture, glide modes, flow stress

\section{INTRODUCTION}

Texture investigations on naturally and experimentally deformed pyrrhotite $\mathrm{Fe}_{1-\mathrm{X}} \mathrm{S}$ by $\mathrm{X}$-ray diffraction are known from previous studies. Naturally deformed pyrrhotite ores in general show a texture with (0001) parallel to the foliation (e.g. v. Gehlen 1962, Bayer and Siemes 1971, Larson 1973). The texture of a naturally and experimentally deformed polycrystalline pyrrhotite ore from Slaettberg was investigated by Kübler (1985b) using X-ray diffraction. The ore shows a very strong initial texture with the

\footnotetext{
'In this study a distinction is made between 'glide mode' and 'slip system': the expression 'glide mode' denotes all deformation mechanisms which are listed in Tab. 1 whereas the expression 'slip systems' denotes only translation gliding.
} 
c-axes preferentially oriented perpendicular to the foliation. Kübler compressed two samples parallel to the foliation. The first sample compressed $12 \%$ at $300^{\circ} \mathrm{C}$ with a strain rate of $1 \times 10^{-5} \mathrm{~s}^{-1}$ shows a tendency to develop an a-axis orientation perpendicular to the compression axis. The other sample compressed $22.1 \%$ at $400^{\circ} \mathrm{C}$ with a strain rate of $7 \times 10^{-6} \mathrm{~s}^{-1}$ developed an a-axis maximum parallel to the compression axis.

To the author's knowledge a study of a series of experiments which demonstrates the texture development of experimentally deformed polycrystalline pyrrhotite as a function of various deformation conditions does not exist. The main aim of the present study is to examine the influence of several parameters on pyrrhotite ores texture development, including the initial texture of the starting material, the deformation temperature and the total strain. The influence of the deformation temperature and the strain rate on the flow stresses of the pyrrhotite ores was also investigated within the bounds of the present study.

The deformation mechanisms of hexagonal pyrrhotite were described earlier (e.g. Buerger 1928, Graf and Skinner 1970, Clark and Kelly 1973, Atkinson 1975, Kübler $1985)^{2}$. To understand the texture development under different conditions a brief review of this subject is necessary. At low temperatures especially at room temperature cataclastic flow occurs. Kinking can occur at room temperature and is of increasing importance with rising temperature. Deformation experiments on polycrystalline pyrrhotite and single crystals lead to the discovery of basal slip $(0001)<10 \overline{1} 0>$ or $<11 \overline{2} 0>$, prism slip $\{10 \overline{1} 0\}<12 \overline{1} 0>$ and twinning $\{10 \overline{1} 2\}<\overline{1} 011>$. Basal slip can be activated already at room temperature. Kübler (1985a) found out that even a small nonparallelism of one or two degrees between compression axis and c-axis is sufficient to activate basal slip. In deformation experiments on single crystals at 200, 300 and $400^{\circ} \mathrm{C}$ he observed prism slip and found that this can only be activated if the angle between compression axis and c-axis exceeds 70 degrees. Twinning does not occur at low temperatures and becomes evident above $250^{\circ} \mathrm{C}$. Some information about the critical resolved shear stress (CRRS) of basal and prism slip at constant strain rates and temperatures of 200,300 and $400^{\circ} \mathrm{C}$ is given in Table 1. The CRRS of prism slip is higher than that of basal slip. In both cases it decreases with increasing temperature but to a different extent. For twinning the CRRS is unknown.

Table 1 Gilde modes in pyrrhotite (Kübler 1985a).

\begin{tabular}{lccc}
\hline glide mode & $\begin{array}{c}\text { strain rate } \\
{\left[\mathrm{s}^{-1}\right]}\end{array}$ & $\begin{array}{c}\text { temp. } \\
{\left[{ }^{\circ} \mathrm{C}\right]}\end{array}$ & $\begin{array}{c}\text { CRRS } \\
{[\mathrm{MPa}]}\end{array}$ \\
\hline $\begin{array}{l}\text { (0001)<1120> } \\
\text { or }<10 \overline{1} 0> \\
\text { slip }\end{array}$ & $10^{-5}$ & 200 & 60 \\
& & 300 & 8 \\
$\{10 \overline{1} 0\}<\overline{1} 2 \overline{1} 0>$ & & 400 & 4.7 \\
slip & $10^{-5}$ & 200 & 115 \\
& & 300 & $38-48$ \\
$\{10 \overline{1} 2\}<\overline{1} 011>$ & & 400 & 7 \\
twinning & $10^{-5}$ & 300 & - \\
\hline
\end{tabular}

\footnotetext{
${ }^{2}$ Investigation on the deformation mechanisms of monoclinic pyrrhotite are unknown.
} 
The texture investigations in this study were done by neutron texture analyses. Polycrystalline ores often show more or less inhomogeneous textures within one specimen. Because of the different sample shapes and sizes required for X-ray texture investigations and deformation experiments it is impossible to measure the texture of the same sample before and after experimental deformation using X-rays. Previous texture investigations by $\mathrm{X}$-rays have shown that there are often uncertainties whether the texture differences of undeformed and deformed samples are the result of the deformation process or the result of local inhomogenities of the starting material (Niederschlag 1992). This is especially the case if only small changes are observed. To avoid this problem in this study texture investigations on a series of naturally and experimentally deformed samples were carried out by neutron diffraction. Neutron texture investigations need no specific sample preparation. Therefore it is possible to measure the texture of the whole volume of each sample before and after experimental deformation, so that a direct comparison of the texture of the undeformed and deformed samples is possible. Even slight changes of the texture due to experimental deformation can be identified. Moreover the use of neutron diffraction allows the investigation of a larger sample volume than with X-ray diffraction. This reduces the importance of local inhomogenities (Niederschlag et al. 1994). The advantages of neutron diffraction for texture investigations are described in detail e.g. by Kleinstuick et al. (1976), Bunge (1989) and Wenk (1993).

To make it easier for the reader to understand a few general aspects about the different types of pyrrhotite and their phase relations need to be mentioned. The structure of pyrrhotite is a derivative of the NiAs structure. The sulfur atoms are arranged in a hexagonal close packing and the iron atoms occupy the octahedra sites. This structure consists of alternating sulfur and iron planes. With the exception of troilite (FeS) all pyrrhotites have iron vacancies. The differences of the various types consist in different iron contents and varying arrangements of iron planes with and without vacancies. The pyrrhotites which are stable at room temperature are presented in Table 2. The nomenclature of the different pyrrhotite types derives from the multiples of the NiAs structure in the direction of the c-axis. Naturally polycrystalline pyrrhotite ores very often consist of a mixture of several types. In the literature the intermediate pyrrhotites are mostly denoted hexagonal although Morimoto et al. (1975a,b) found them to be orthorhombic. In this study they are also denoted hexagonal. For simplification the indices of the hexagonal $1 \mathrm{C}$ pyrrhotite with the lattice constants $a_{0}=b_{0}=3,44 \AA$,

Table 2 Various pyrrhotite types stable at room temperature (after Morimoto et al. 1975a,b)

\begin{tabular}{lllll}
\hline structure type & formula & $\begin{array}{l}\text { metal content } \\
\text { at. } \%\end{array}$ & $\begin{array}{l}\text { ratio metal/ } \\
\text { sulphur }\end{array}$ & symmetry \\
\hline $\begin{array}{l}\text { troilite: } \\
\text { 2C }\end{array}$ & $\mathrm{FeS}$ & $50.00 \%$ & 1.000 & hexagonal \\
$\begin{array}{l}\text { monoclinic } \\
\text { 4C }\end{array}$ & $\begin{array}{l}\text { pyrrhotite: } \\
\mathrm{Fe}_{7} \mathrm{~S}_{8}\end{array}$ & $46.67 \%$ & 0.875 & monoclinic \\
$\begin{array}{l}\text { intermediate } \\
\text { 5C }\end{array}$ & $\begin{array}{l}\mathrm{Fe}_{9} \mathrm{~S}_{10} \\
\mathrm{Fe}_{10} \mathrm{~S}_{11}\end{array}$ & $47.37 \%$ & & \\
$5.5 \mathrm{C}$ & $\mathrm{Fe}_{11} \mathrm{~S}_{12}$ & $47.67 \%$ & 0.900 & ortohrhombic \\
6C & & $47.83 \%$ & 0.909 & orthorhombic \\
\hline
\end{tabular}


$c_{0}=5,76 \AA$ are used. The phase relations of pyrrhotite below $350^{\circ} \mathrm{C}$ were described by Kissin and Scott (1982). For the present study the most important subject to know about is the phase transformation from monoclinic to hexagonal pyrrhotite at $254^{\circ} \mathrm{C}$. This explanes the hexagonal symmetry of all originally monoclinic samples which were deformed experimentally at 300 and $400^{\circ} \mathrm{C}$. The transition of pyrrhotite from the monoclinic to the hexagonal phase causes only small changes in the metrics of the structure. Therefore the hexagonal (0001) plane is equivalent to the monoclinic planes $(117)+(008)$ and $(11 \overline{2} 0)$ corresponds to $(040)+(620)$. In X-ray diffraction diagrams the (117) and (008) as well as (040) and (620) are largely overlapping. In polycrystalline pyrrhotite it is possible to identify monoclinic and hexagonal phases by $\mathrm{X}$-ray diffraction analysis (Arnold 1966).

\section{STARTING MATERIAL}

The first investigated ore from the Sullivan Mine, Canada has an average composition of $90.1 \pm 0.9 \%$ pyrrhotite, $4.9 \pm 0.7 \%$ sphalerite, $0.6 \pm 0.2 \%$ galena, $0.6 \pm 0.2 \%$ chalcopyrite, $0.1 \pm 0.1 \%$ arsenopyrite, and $3.7 \pm 0.6 \%$ gangue minerals and holes. The grain size varies within a range from 0.1 to $0.6 \mathrm{~mm}$. The pyrrhotite is mainly hexagonal which was confirmed by Arnold's (1966) method. The iron content of $47.33 \pm 0.16$ at.-\% was established by electron microprobe analyses. Investigations by reflected light microscopy on polished sections showed many kinks, but no twins within the pyrrhotite. The pyrrhotite shows a distinct initial texture with (0001) parallel to the foliation (see Figure 2-4, first column). The texture can be described as fibre texture with the $(1 \overline{1} 0)$ poles concentrated on great circles which show some maxima. The (1012) pole figures show small circles with pole angles of approximately 44 degrees. A clear (0001) maximum can be seen.

The second investigated ore from the Cerro de Pasco Mine, Peru has an average composition of $89.9 \pm 1.0 \%$ pyrrhotite, $1.2 \pm 0.3 \%$ pyrite and arsenopyrite which are closely intergrown, $0.9 \pm 0.3 \%$ sphalerite, $0.2 \pm 0.1 \%$ galena, and $7.8 \pm 0.9 \%$ gangue minerals and holes. The grain size of the pyrrhotite varies strongly from $0.01 \mathrm{~mm}$ to $1.5 \mathrm{~mm}$. The pyrrhotite is mainly monoclinic and contains $46.75 \pm 0.29$ at. $\%$ Fe. The pyrrhotite shows subgrain structures and kinks, but no twins. The initial texture of the pyrrhotite is weak and very inhomogeneous within the specimen (see Figure 6). In the $(040) /(620)$ and $(117) /(008)$ pole figures the distribution of the maxima and the pole density vary distinctly. A more detailed description of both ores which is not necessary for the purpose of this paper is given by Niederschlag (1994).

\section{EXPERIMENTAL PROCEDURE}

\section{Sample Preparation}

Cylindrical samples, $30 \mathrm{~mm}$ long and $15 \mathrm{~mm}$ in diameter, were prepared from the specimens. Because the Sullivan ore has a distinct initial texture, the samples were cut with angles of 8,35 , and 82 degrees between cylinder axis and c-axis maximum. These angles are mean values. A variation of up to 4 degrees is possible. The cylinders of the ore from Cerro de Pasco were all cut in the same direction. 


\section{Compression Experiments}

The samples were deformed by axial compression. The confining pressure at room temperature was chosen at $400 \mathrm{MPa}$ in order to prevent premature brittle fracture of the samples whereas $300 \mathrm{MPa}$ were chosen at higher temperatures. The confining pressure medium was silicone oil. The samples were encapsuled in aluminium jackets.

The tests with the samples from Sullivan were performed with a constant strain rate of about $3 \times 10^{-5} \mathrm{~s}^{-1}$ and temperatures of $25,100,200,300$, and $400^{\circ} \mathrm{C}$. The accessible total strain increases at higher temperatures because of decreasing CRRS and the increasingly ductile behaviour. In the experiments total strain was increased with temperature to study the resulting differences in texture (Table 3). The tests with the samples from Cerro de Pasco were carried out with strain rates of about $3 \times 10^{-5}$ $\mathrm{s}^{-1}$. Temperatures were fixed at 200 and $400^{\circ} \mathrm{C}$, and total strain was chosen in two orders, the first one between 12.4 and $14.6 \%$, and the second one between 25.0 and $26.5 \%$ (Table 4), but one sample was deformed up to $34.7 \%$.

After experimental deformation the shape of the samples differed distinctly (Figure 1a-c). The shapes of the samples from Sullivan demonstrate the influence of the compression direction. Especially the conjugated shear fractures of sample Su8-300 show a smaller degree of plastic deformation for this compression direction than for the other samples. In samples which were compressed with an angle of 35 degrees to the c-axis maximum the deformation partly takes place by ductile shear parallel to

Table 3 Deformation experiments on polycrystalline pyrrhotite from Sullivan mine, Canada.

\begin{tabular}{|c|c|c|c|c|c|c|c|c|}
\hline \multirow{2}{*}{$\begin{array}{l}\text { sample } \\
\text { Su8-25 }\end{array}$} & \multirow{2}{*}{$\begin{array}{r}\text { temp. } \\
{\left[{ }^{\circ} \mathrm{C}\right]} \\
25\end{array}$} & \multirow{2}{*}{$\begin{array}{c}\begin{array}{c}\text { conf. } \\
\text { press. }\end{array} \\
\text { [MPA] } \\
400\end{array}$} & \multirow{2}{*}{$\begin{array}{c}\begin{array}{c}\text { average } \\
\text { strain } \\
\text { rate } \\
{\left[s^{-1}\right]}\end{array} \\
2.5 \cdot 10^{-5}\end{array}$} & \multirow{2}{*}{$\begin{array}{r}\begin{array}{c}\text { total } \\
\text { strain }\end{array} \\
{[\%]} \\
13.8 \\
\end{array}$} & \multicolumn{2}{|c|}{$\begin{array}{c}\text { diff. stress } \\
\text { at } x \% \text { strain } \\
{ }_{10 \%}^{[M P a]}{ }_{20 \%}\end{array}$} & \multicolumn{2}{|c|}{$\begin{array}{c}\text { max. diff. } \\
\text { stress } \\
\text { (at \% strain) } \\
{[M P a]}\end{array}$} \\
\hline & & & & & 1028 & - & 1031 & ( 8.8$)$ \\
\hline Su8-100 & 100 & 300 & $2.9 \cdot 10^{-5}$ & 17.3 & 755 & - & 763 & (11.4) \\
\hline Su8-200 & 200 & 300 & $3.2 \cdot 10^{-5}$ & 24.5 & 476 & 480 & 485 & (22.5) \\
\hline Su8-300 & 300 & 300 & $3.5 \cdot 10^{-5}$ & 27.3 & 120 & 130 & 131 & (19.4) \\
\hline Su8-400 & 400 & 300 & $3.5 \cdot 10^{-5}$ & 27.1 & 100 & 123 & 130 & (27.0) \\
\hline Su35-25 & 25 & 400 & $2.7 \cdot 10^{-5}$ & 18.4 & 969 & - & 984 & (15.9) \\
\hline Su35-100 & 100 & 300 & $2.9 \cdot 10^{-5}$ & 21.4 & 737 & 754 & 762 & (17.5) \\
\hline Su35-200 & 200 & 300 & $3.1 \cdot 10^{-5}$ & 24.4 & 444 & 493 & 504 & (23.2) \\
\hline Su35-300 & 300 & 300 & $3.3 \cdot 10^{-5}$ & 31.9 & 174 & 223 & 246 & (29.2) \\
\hline Su35-400 & 400 & 300 & $3.6 \cdot 10^{-5}$ & 32.5 & 71 & 102 & 127 & (32.4) \\
\hline Su82-25 & 25 & 400 & $2.9 \cdot 10^{-5}$ & 20.6 & 1090 & 1188 & 1193 & (18.9) \\
\hline Su82-100 & 100 & 300 & $2.9 \cdot 10^{-5}$ & 24.5 & 669 & 724 & 732 & $(24.2)$ \\
\hline Su82-300 & 300 & 300 & $3.3 \cdot 10^{-5}$ & 34.8 & 124 & 142 & 171 & (34.8) \\
\hline Su $82-400$ & 400 & 300 & $3.6 \cdot 10^{-5}$ & 34.5 & 51 & 58 & 79 & (34.5) \\
\hline
\end{tabular}

Note: The angles between compression axis and initial c-axis maximum were determined by neutron diffraction pole figures: $\mathrm{Su} 8=8$ degrees, $\mathrm{Su} 35=35$ degrees, Su82 $=82$ degrees. 
Table 4 Deformation experiments on polycrystalline pyrrhotite from Cerron de Pasco mine, Peru.

\begin{tabular}{|c|c|c|c|c|c|c|c|c|}
\hline \multirow{2}{*}{$\begin{array}{l}\text { sample } \\
\text { CP200-5a }\end{array}$} & \multirow{2}{*}{$\begin{array}{l}\text { temp. } \\
{\left[{ }^{\circ} \mathrm{C}\right]} \\
200\end{array}$} & \multirow{2}{*}{$\begin{array}{c}\begin{array}{c}\text { conf. } \\
\text { press. }\end{array} \\
\text { [MPA] }\end{array}$} & \multirow{2}{*}{$\begin{array}{c}\begin{array}{c}\text { average } \\
\text { strain } \\
\text { rate } \\
{\left[s^{-1}\right]}\end{array} \\
2.8 \cdot 10^{-5}\end{array}$} & \multirow{2}{*}{$\begin{array}{c}\text { total } \\
\text { strain } \\
\\
{[\%]} \\
12.4\end{array}$} & \multicolumn{2}{|c|}{$\begin{array}{c}\text { diff. stress } \\
\text { at } x \% \text { strain } \\
{ }_{10 \%}^{[M P a]}{ }^{[M \%} 20 \%\end{array}$} & \multicolumn{2}{|c|}{ 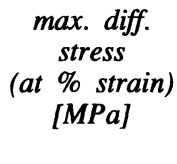 } \\
\hline & & & & & 437 & - & 447 & (12.4) \\
\hline CP400-5a & 400 & 300 & $3.5 \cdot 10^{-5}$ & 14.6 & 102 & - & 117 & (14.6) \\
\hline CP400-5b & 400 & 300 & $3.5 \cdot 10^{-5}$ & 26.5 & 123 & 156 & 160 & (26.4) \\
\hline CP400-5c & 400 & 300 & $3.3 \cdot 10^{-5}$ & 34.7 & 138 & 188 & 197 & (29.7) \\
\hline CP200-6a & 200 & 300 & $6.6 \cdot 10^{-6}$ & 12.9 & 383 & - & 395 & (12.9) \\
\hline CP200-6b & 200 & 300 & $6.8 \cdot 10^{-6}$ & 25.0 & 364 & 387 & 390 & (23.2) \\
\hline CP400-6a & 400 & 300 & $7.7 \cdot 10^{-6}$ & 14.5 & 98 & - & 116 & (14.3) \\
\hline CP400-6b & 400 & 300 & $7.3 \cdot 10^{-6}$ & 26.1 & 63 & 85 & 94 & (25.9) \\
\hline CP400-7a & 400 & 300 & $8.2 \cdot 10^{-7}$ & 14.3 & 103 & - & 123 & (14.3) \\
\hline $\mathrm{CP} 400-7 \mathrm{~b}$ & 400 & 300 & $7.5 \cdot 10^{-7}$ & 26.5 & 88 & 119 & 129 & (24.2) \\
\hline
\end{tabular}

the foliation of the ore. The samples compressed with 82 degrees to the c-axis maximum showed homogeneous deformation. The cylinders of the ore from Cerro de Pasco sometimes showed an uneven shape with some bulges caused by squeezed gangue minerals (Figure 1d).

Investigations by reflected light microscopy did not indicate dynamic recrystalisation even not in samples deformed at the higher temperatures.

\section{Neutron texture investigations}

Neutron texture analyses on the Sullivan ore were performed at the diffractometer TEX2 at GKSS research centre Geesthacht using the angle dispersive method (Brokmeier 1989, Gertel 1992). Pole figures of the (1120) and (1012) reflections were measured. From these pole figures the ODF (orientation density function) was calculated by means of the iterative series expansion method using the positivity condition (Dahms and Bunge 1989a,b, Dahms 1992) with a degree of expansion of 22. From this the pole figure of the (0001) reflection was recalculated. A preceding comparison of calculated and measured pole figures of the same reflections established that two measured pole figures were sufficient to calculate the ODF. The pole figures of the measured reflections

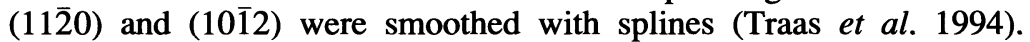

Neutron texture analyses on the samples from Cerro de Pasco were performed at the diffractometer NSWR at the Joint Institute for Nuclear Research in Dubna / Moscow district, Russia by using the time-of-flight method (Feldmann 1989, Helming et al. 1992). With this method it is possible to measure pole figures of all existing reflections simultaneously. In this study the pole figures of the overlapping monoclinic reflections $(040) /(620)$ and $(008) /(117)$, which correspond to the reflections $(11 \overline{2} 0)$ and $(0001)$ in the hexagonal pyrrhotite, were used to present the texture of the undeformed and deformed samples. 


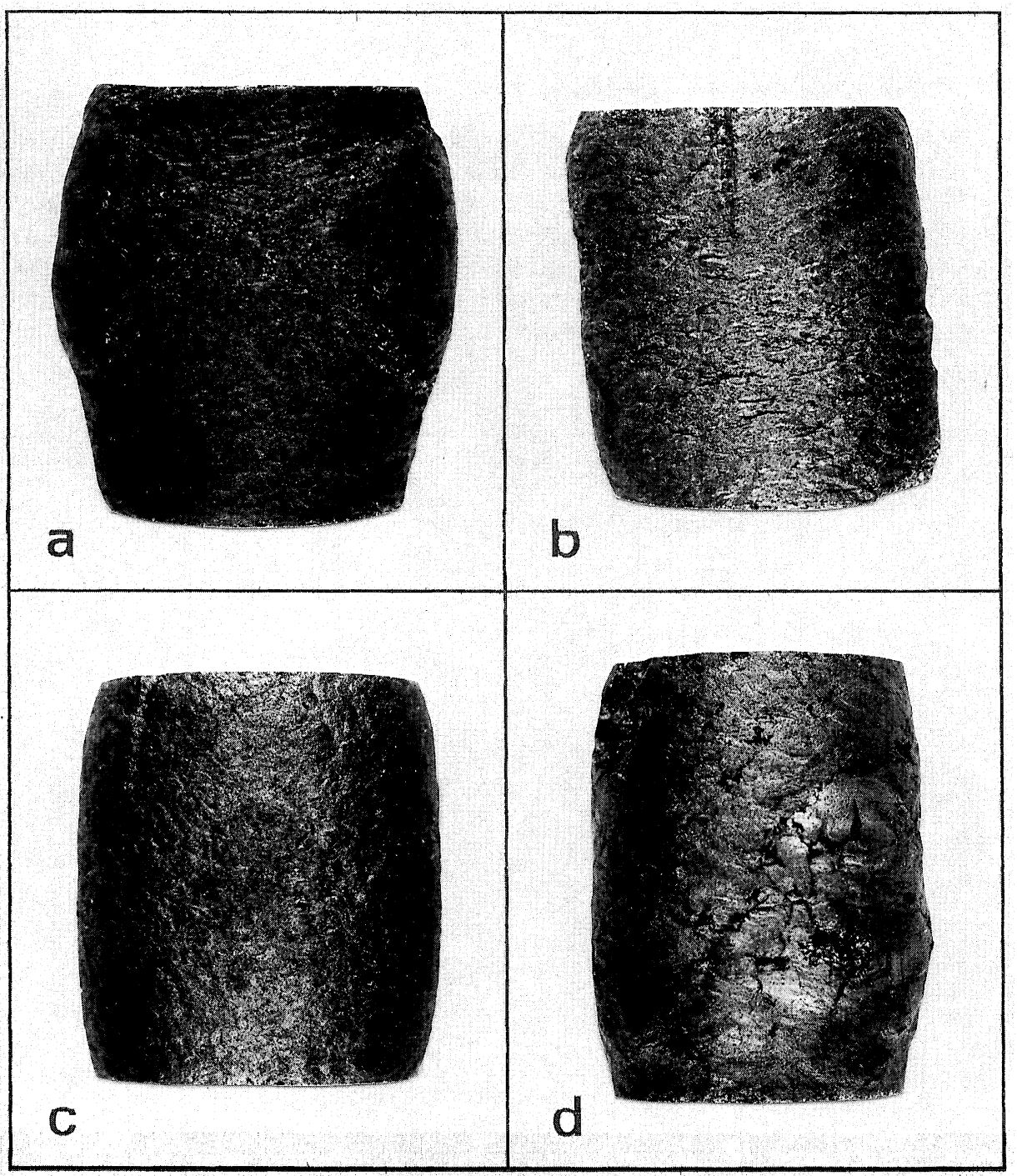

Figure 1 Experimentally deformed samples of pyrrhotite ores from Sullivan mine, Canada and Cerro de Pasco mine, Peru: (a) Su8-300, (b) Su35-300, (c) Su82-400, (d) CP400-6b.

All pole figures are presented in equal area projection and the compression axis is situated perpendicular to the projection plane. In the case of the Sullivan ore the contour intervals are 0.25 m.r.d. (multiples of random density) for $(11 \overline{2} 0)$ and (1012) pole figures and 0.50 m.r.d. for (0001) pole figures. For the Cerro de Pasco ore the contour intervals are 0.20 m.r.d. for pole figures of the overlapping reflections $(040) /(620)$ and (117)/ (008). Areas below 1.0 m.r.d. are always dotted. 


\section{TEXTURE BEFORE AND AFTER EXPERIMENTAL DEFORMATION}

\section{Pyrrhotite from Sullivan}

Pole figures of the measured $(11 \overline{2} 0)$ and (1012) reflections and the calculated (0001) pole figures (Figures 2-4) show the development of the texture under different deformation conditions in comparison with the texture of the undeformed material. Samples compressed at angles of 8 degrees (Figure 2) and 35 degrees (Figure 3) to the initial c-axis maximum show a progressive tendency of the c-axes to orient parallel to the compression axis. Samples compressed with an angle of 82 degrees to the initial c-axis maximum (Figure 4) show the development of an a-axis maximum parallel to

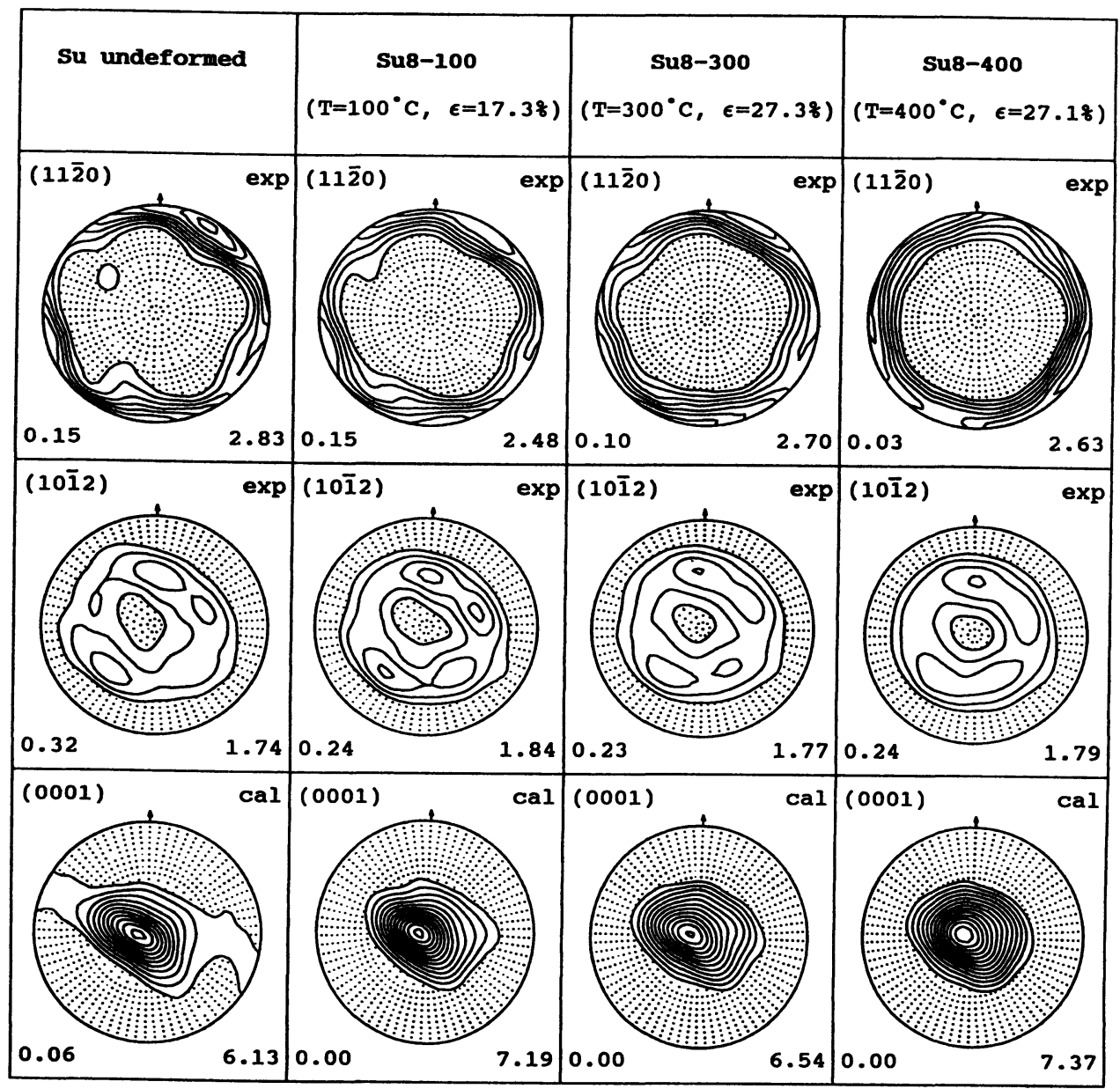

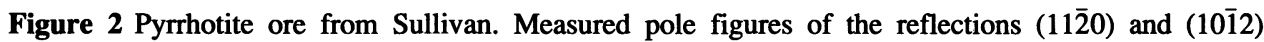
and calculated (0001) pole figures. Texture development with increasing temperature and total strain on samples with an angle of 8 degrees between compression axis and initial c-axis maximum. 


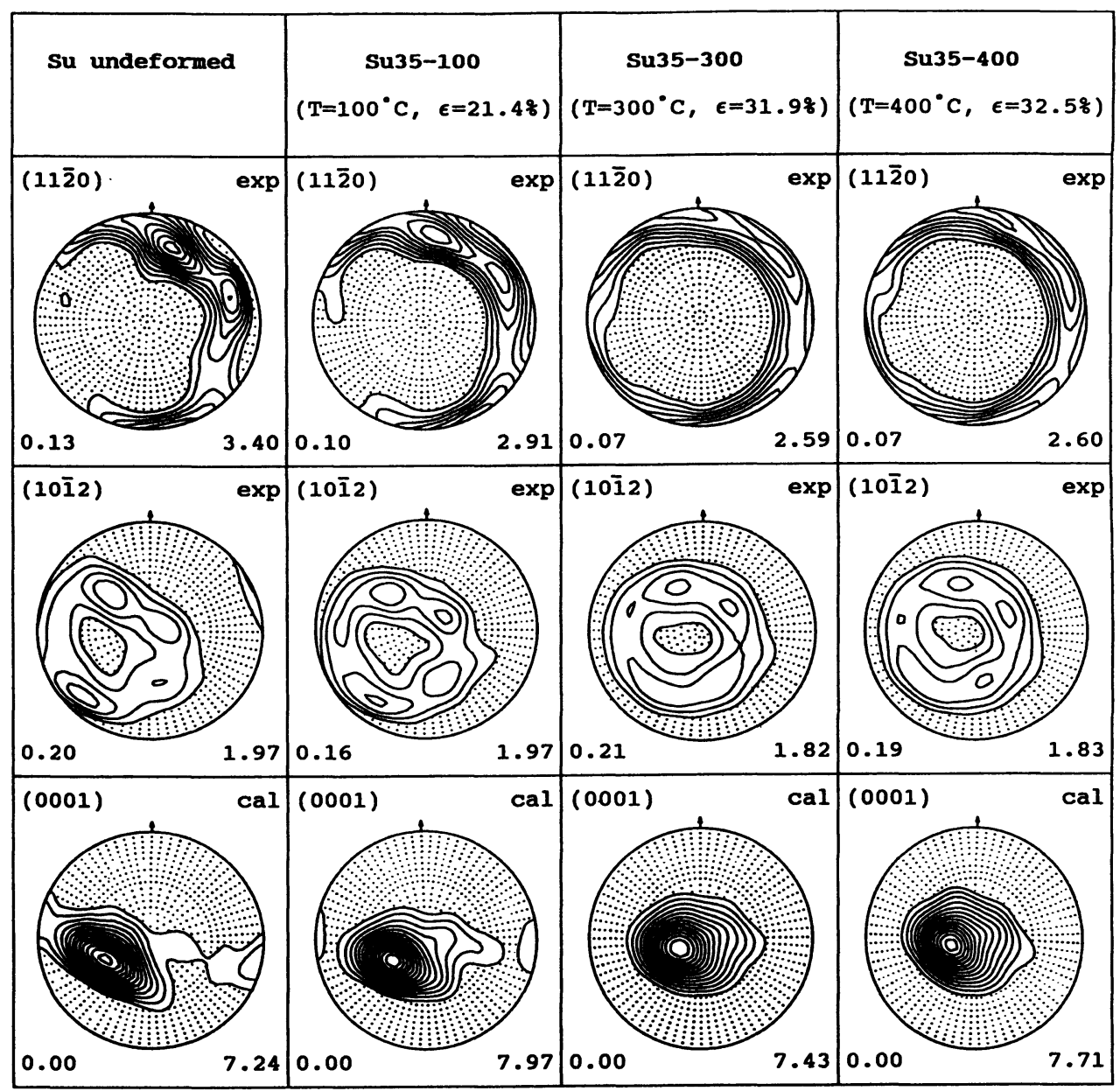

Figure 3 Pyrrhotite ore from Sullivan. Measured pole figures of the reflections (1120) and (1012) and calculated $(0001)$ pole figures. Texture development with increasing temperature and total strain on samples with an angle of 35 degrees between compression axis and initial c-axis maximum.

the compression axis at $25^{\circ} \mathrm{C}$ and $100^{\circ} \mathrm{C}$. On the other hand widespread (1120)-maxima in the vicinity of the primitive circle of the pole figures are visible after the deformation at 300 and $400^{\circ} \mathrm{C}$. The angle between the c-axis maximum and the compression axis is approximately 40 degrees. The (0001) maxima obviously tend to shift to the centres of the pole figures with increasing temperature and total strain. The plot of the angle between the c-axis maxima and the centres of the pole figures (Figure 5) shows this continuing reorientation of (0001) perpendicular to the compression axis with increasing temperature and total strain.

These results should be compared to results of deformation experiments on pyrrhotite from Slaettberg by Kübler (1985b). The initial texture of the Slaettberg ore is very 


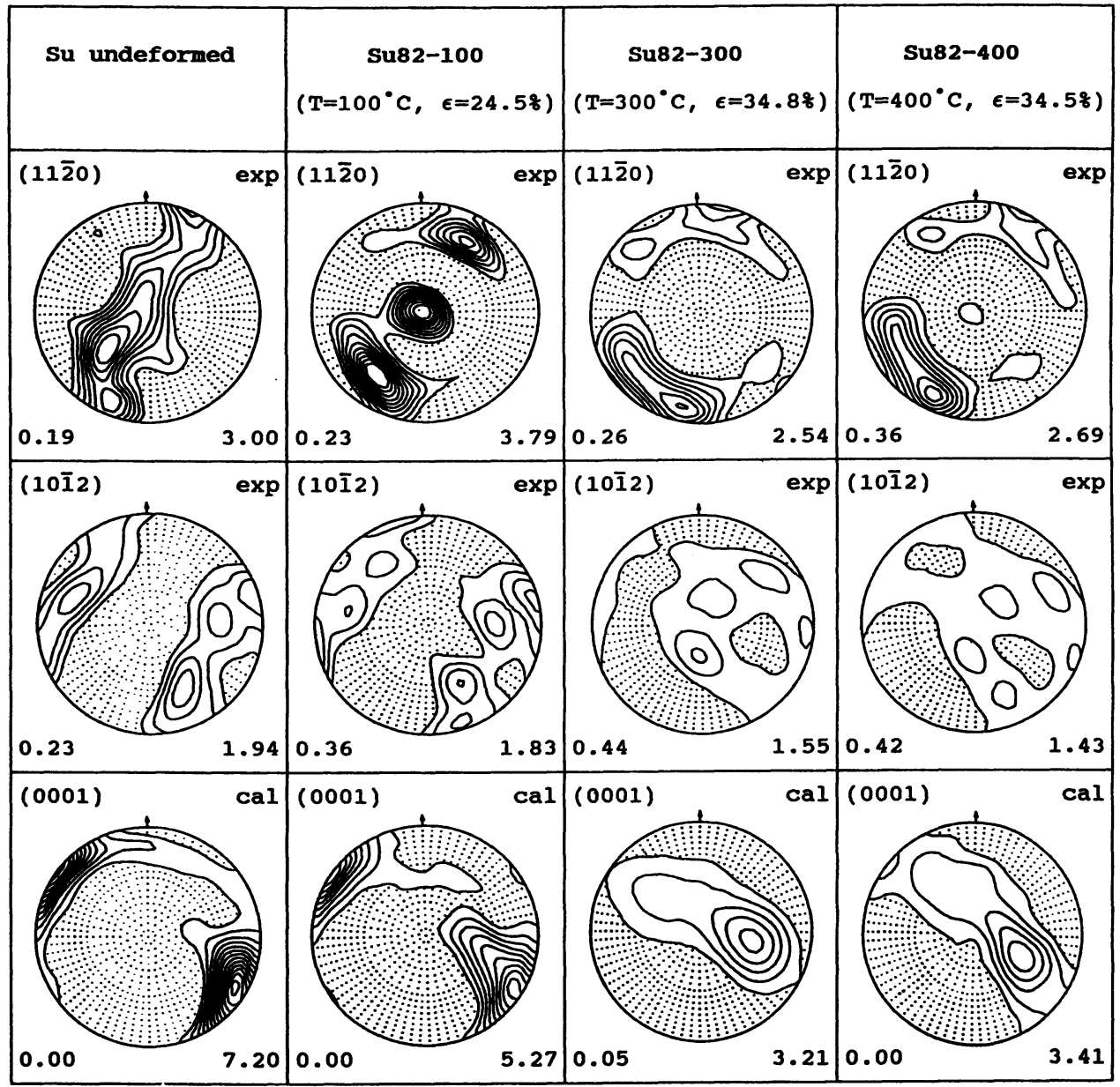

Figure 4 Pyrrhotite ore from Sullivan. Measured pole figures of the reflections (1120) and (1012) and calculated (0001) pole figures. Texture development with increasing temperature and total strain on samples with an angle of 82 degrees between compression axis and initial c-axis maximum.

similar to that of the Sullivan ore, but the texture development between the Sullivan ore and the Slaettberg ore is surprisingly different. In Kübler's experiments the a-axis maximum perpendicular to the compression axis develops at the lower temperature $\left(300^{\circ} \mathrm{C}\right)$ and after compression of only $12 \%$ while the a-axis maximum parallel to the compression axis arose both at higher temperature $\left(400^{\circ} \mathrm{C}\right)$ and total strain of $22.1 \%$. This is in contrast to the present study which shows the development of an a-axis maximum perpendicular to the compression axis at the higher temperature and higher total strain. The reasons for these different results remain unclear. The differences in strain rate may influence the sharpness of a developing texture at best but not the kind of texture. 


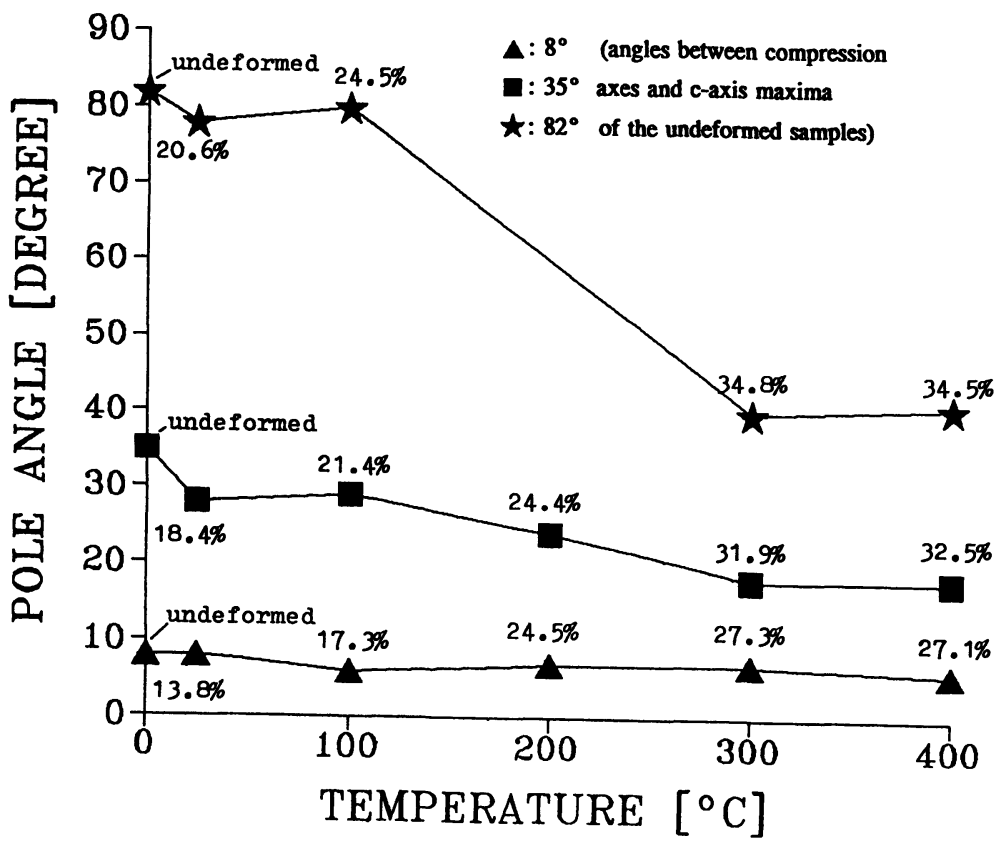

Figure 5 Pyrrhotite ore from Sullivan. Reorientation of the c-axis maximum vs. temperature after experimental deformation. The total strain of the deformed samples is indicated.

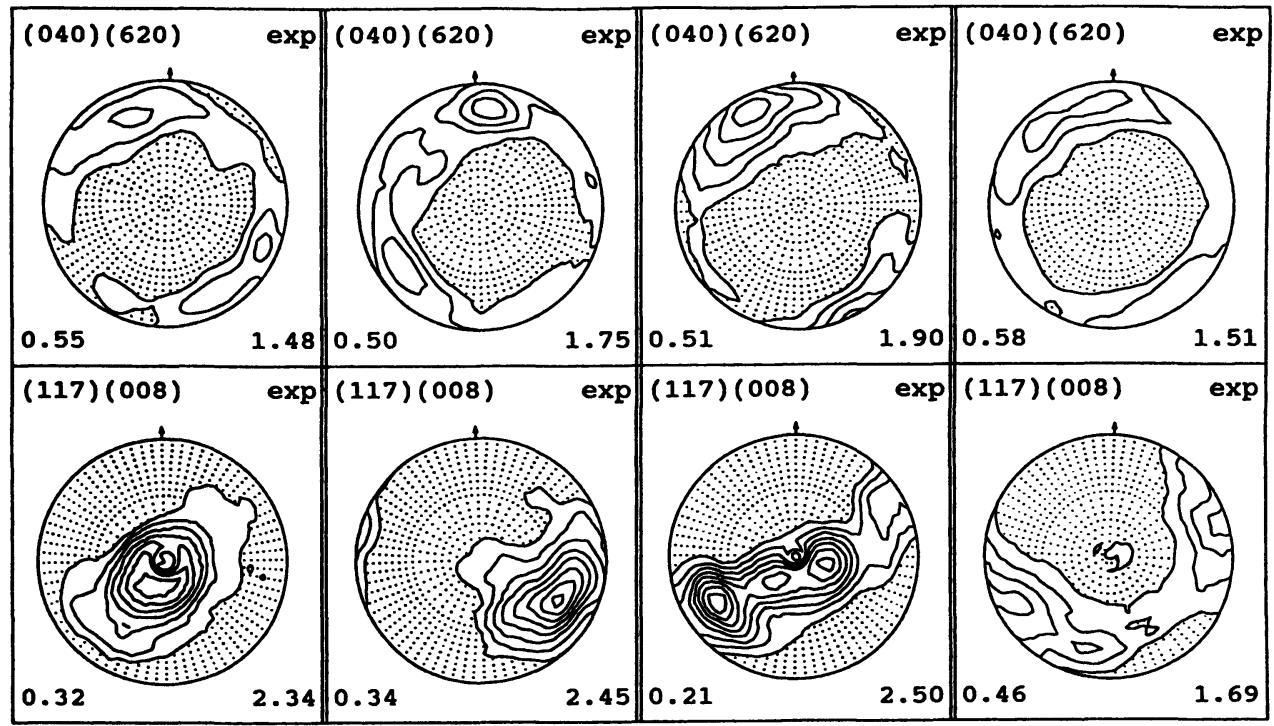

Figure 6 Pyrrhotite ore from Cerro de Pasco. Measured pole figures of the overlapping reflections $(040) /(620)$ and $(117) /(008)$. Comparison of the texture of four underformed samples. 


\section{Pyrrhotite from Cerro de Pasco}

The texture development after experimental deformation is shown in Figure 7. The phase transformation from monoclinic to hexagonal in samples deformed at $400^{\circ} \mathrm{C}$ was proved by X-ray investigations (Arnold 1966) on all samples. Therefore hexagonal indices are used for the pole figures of these samples. After deformation under different conditions all samples show a tendency of $(117) /(008)$ respectively $(0001)$ to orient perpendicular to the compression axis while the (040)/(620) respectively $(1120)$ poles concentrate on great circles along the primitive circle. This is analogous to the texture development of the Sullivan ore compressed with angles of 8 and 35 degrees to the initial c-axis maximum at all investigated temperatures. The inhomogenity of the starting material prevented us from obtaining results about the texture development as a function of temperature and strain rate. Only the influence of total strain becomes obvious. An increase of total strain leads to a stronger texture of $(117) /(008)$ respectively $(0001)$ perpendicular to the compression axis.

\section{EFFECT OF THE ACTIVATED GLIDE MODES ON THE TEXTURE DEVELOPMENT}

The following passage is an attempt to explain the reasons for the variable texture development in different compression directions, which is demonstrated by the

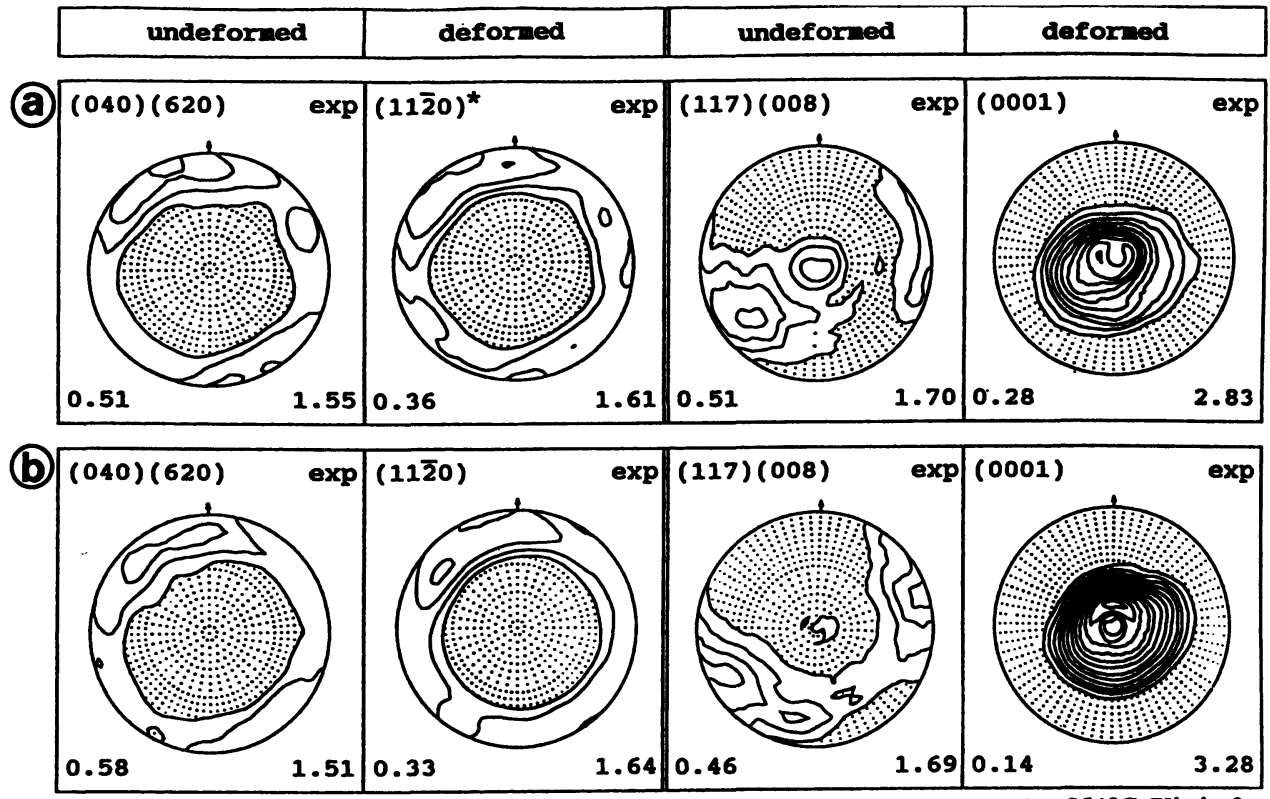

Hexagonal indices are used because of the phase transformation monoclinic - hexagonal at $254^{\circ} \mathrm{C} \mathrm{(Kissin} \mathrm{\&}$ Scott 1982).

Figure 7 Pyrrhotite ore from Cerro de Pasco. Comparison of the texture of two undeformed and experimentally deformed samples with different total strain. a) CP400-7a, b) CP400-7b. 
experiments with the Sullivan ore. This is caused by the different conditions for the activation of the various glide modes in pyrrhotite. The dependency of the activation of the glide modes on the compression direction is shown by Schmid's law (Schmid and Boas 1935).

$\tau=\sigma \cdot \mathrm{m}=\sigma \cdot \cos \chi \cdot \cos \lambda$

$\tau=$ shear stress

$\chi=$ angle between direction of the main stress $\mathrm{s}$ and glide direction

$\lambda=$ angle between direction of the main stress $s$ and normal on the glide plane

$\mathrm{m}=$ orientation factor

Figure 8 shows the orientation factors for the glide modes in hexagonal pyrrhotite. One has to keep in mind that this kind of representation in the strict sense is only valid for single crystals. For the polycrystalline pyrrhotite ore it has to be considered as a simplified model in order to illustrate the orientation factors. From the pole figures of the starting material the precise position of the a-axis maximum cannot be determined. Therefore a continous range for the position of the compression axes in relation to the c-axes is possible. This is taken into account by the presentation of the possible compression directions as dotted lines in Figure 8. The presentation of the orientation factors is given to illustrate the effect of the glide modes briefly. Taylor calculation would probably give more informations, but this is reserved to future work.

In the samples compressed with an angle of 8 degrees to the c-axis maximum the orientation factors for basal slip $(0001)<10 \overline{1} 0\rangle$ or $\langle 11 \overline{2} 0\rangle$ and prism slip $\{10 \overline{10}\}$ $<12 \overline{1} 0>$ are small for most crystal orientations. In the 35 degrees samples favourable conditions exist for the activation of basal slip for most crystals. Prism slip is more likely to be activated than in the 8 degrees samples. Basal slip seems to be most favourable for both the 8 and the 35 degrees samples because of its very low CRSS (Table 1). This may be an explanation for the fact that the (0001) glide planes tend

basal slip $(0001)<10 \overline{1} 0>$

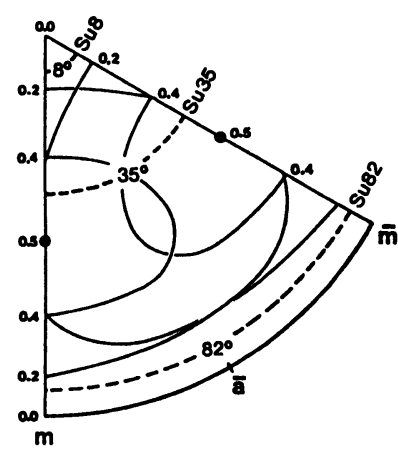

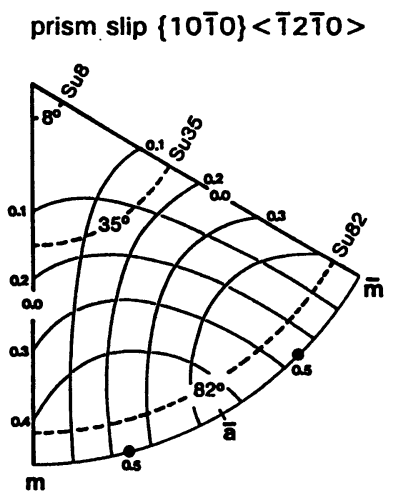

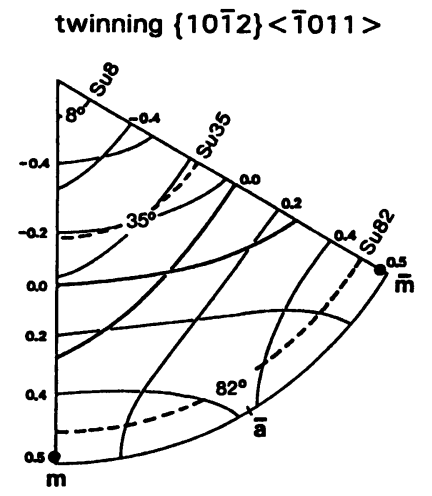

Figure 8 Orientation factors for the different glide modes in hexagonal pyrrhotite, ratio c/a $=1.67$. Equal area projection. The dotted lines represent all possibilities of compression directions for the three sample orientations (see text). 
to orient perpendicular to the compression axis. The same conditions are probably responsible for the texture development in the experimentally deformed samples from Cerro de Pasco.

As already mentioned twinning $\{10 \overline{1} 2\}<\overline{1} 011>$ becomes significant at temperatures above $200^{\circ} \mathrm{C}$. Presuming that all the pyrrhotite grains in the samples have orientations of approximately 8 and 35 degrees, respectively, to the compression axis, twinning is theoretically impossible. Nevertheless investigations on polished sections by reflected light microscopy show some twins after the deformation at 300 and $400^{\circ} \mathrm{C}$. The reason for this is that within the polycrystalline material the grains are widely distributed around the ideal 8 or 35 degrees orientation of course. According to Schmid's law twinning can only take place if, within the deformation plane, the compression axis is oriented with an angle of 45 degrees or more to the glide plane. Referring to the lattice constants of the hexagonal 1C-Pyrrhotite the normal of the (1012)-plane defines an angle of 44.03 degrees with the c-axis. Twinning is most likely if the angle between the c-axis and the compression axis is 90.97 degrees. In the investigated samples twins can mostly be observed in grains with kinks which are oriented nearly perpendicular to the compression axis. This is due to the fact that kinking is most probable if the compression axis is parallel to the (0001) plane, i.e. perpendicular to the c-axis.

In the case of the 82 degrees samples the small values of the orientation factors for basal slip show that this slip system is not favourate to be activated while prism slip and twinning can easily be activated. The activation of prism slip becomes obvious by the development of a (1120)-maximum perpendicular to the compression axis in the pole figures of samples which were deformed up to $100^{\circ} \mathrm{C}$. At 300 and $400^{\circ} \mathrm{C}$ the texture development is completely different. A tendency of the c-axes to reorient parallel to the compression axis can be seen. The onset of twinning in suitable oriented grains causes a sudden change of their orientation and subsequently basal slip becomes much more favourable. As a result of the reorientation the (0001)-planes again tend to orient perpendicular to the compression axis.

\section{EFFECT OF THE TEMPERATURE AND STRAIN RATE ON THE FLOW STRESS}

The flow stress of the pyrrhotite ore from Sullivan decreases with increasing temperature. This is depicted in Figure 9 where the differential stress at $10 \%$ strain is plotted vs. temperature and compared with data of similar experiments by Clark and Kelly (1973) and Atkinson (1975). The stress at $10 \%$ strain decreases with increasing temperature because CRSS decreases for the different glide modes (Table 1) and the prevailing mode of deformation changes, i.e. at higher temperatures the ductile behaviour is enhanced. This was confirmed by the study of the microstructure of the deformed samples from Sullivan by means of reflected light microscopy. Cataclastic flow was only observed at 25 and $100^{\circ} \mathrm{C}$. Kinking occured at all temperatures. Only a few twins developed in samples which were deformed at $200^{\circ} \mathrm{C}$ whereas twinning is of increasing importance at 300 and $400^{\circ} \mathrm{C}$.

At temperatures between 25 and $200^{\circ} \mathrm{C}$ large differences between the flow stresses of the Sullivan ore and the Sudbury ores of Clark and Kelly and Atkinson can be observed. Confining pressure may affect the strength of pyrrhotite only at low temperatures when cataclastic flow influences the deformation behaviour. Intracrystalline flow processes which are dominant at higher temperatures are unaffected by confining 


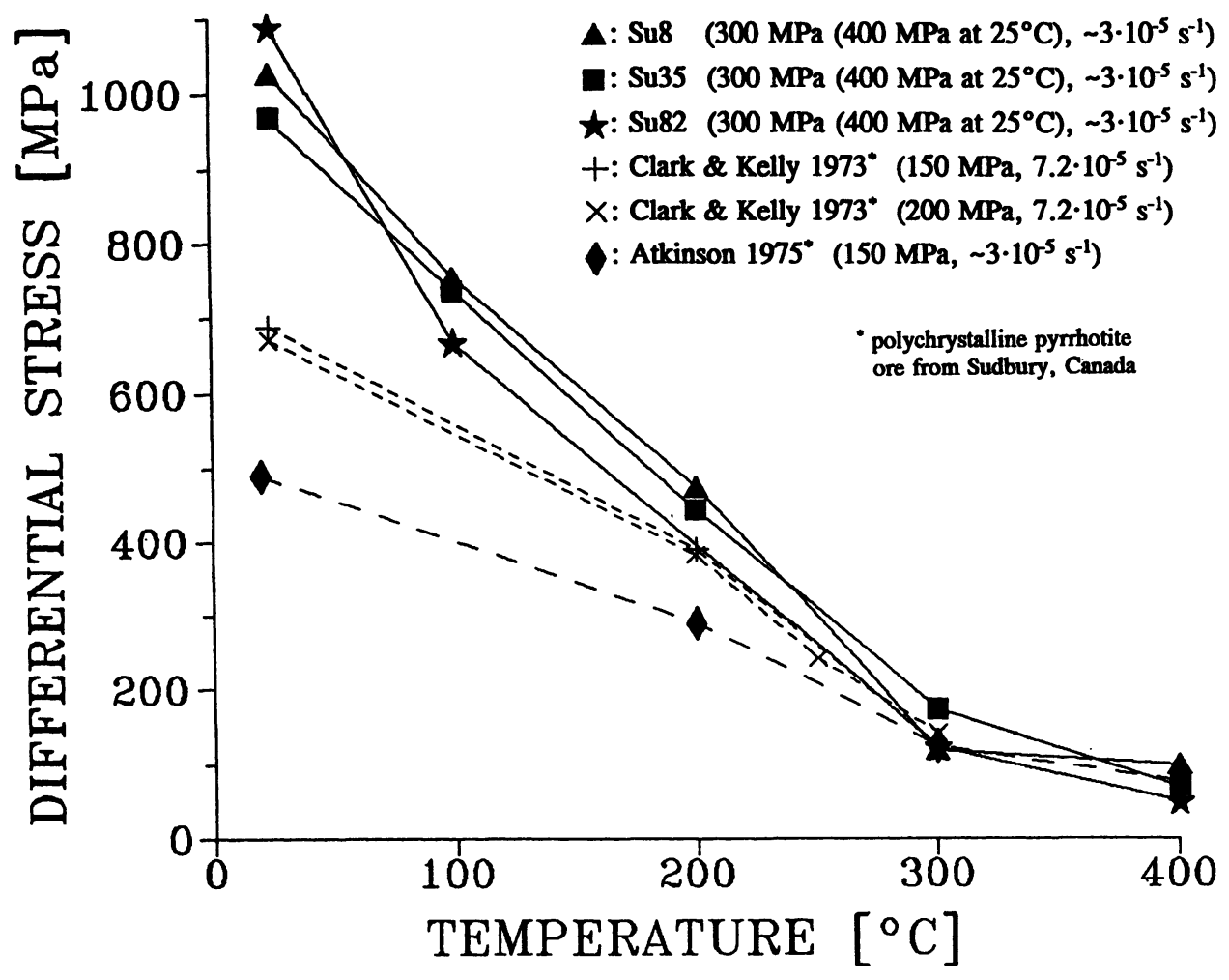

Figure 9 Pyrrhotite ore from Sullivan. Differential stress at $10 \%$ strain vs. temperature in comparison with data at similar conditions of Clark and Kelly (1973) and Atkinson (1975), strain rates of approximately $3 \times 10^{-5} \mathrm{~s}^{-1}$ and $7 \times 10^{-5} \mathrm{~s}^{-1}$.

pressure. This was also reported by Clark and Kelly (1973) who found out that the strength of pyrrhotite is nearly independent of confining pressure in the "purely ductile field above about $200^{\circ} \mathrm{C}$ ". Differences in confining pressure could be an explanation for the higher strength of the Sullivan ore which was compressed at higher confining pressure than the other ores. But then the question remains why there are differences in strength in the ores from Atkinson and Clark and Kelly which were deformed at the same confining pressure.

A reason for the strength differences in the field of plastic deformation may be the difference in grain size. Small grain sizes cause larger flow stresses because the grain boundaries act as obstacles for the dislocation gliding especially at the beginning of plastic deformation. With increasing deformation and therefore increasing density of dislocations the influence of grain size on the strength decreases (Böhm 1987). The Sullivan ore which contains pyrrhotite with a grain size from 0.1 to $0.6 \mathrm{~mm}$ shows the highest strength whereas the Sudbury ore of Clark and Kelly (1973) with a grain size between $1 \mathrm{~mm}$ and several centimeters, and the Sudbury ore of Atkinson (1975) with a mean grain diameter of $1.53 \mathrm{~mm}$ have lower strength. 
The possible influence of impurities on the three ores can hardly be estimated. Clark and Kelly give no detailed information about this. Its only said that impurities range from 5 to 10 vol.-\%. The impurities in the Sullivan ore vary strongly, but no regularity in strength can be deduced from the content of other minerals. E. g. sample Su8-100 contains $14.2 \%$ sphalerite whereas sample Su35-100 contains $1.3 \%$. At temperatures below about $200^{\circ} \mathrm{C}$ sphalerite is weaker than pyrrhotite (Siemes and Hennig-Michaeli 1985), but sample Su8-100 still has a larger strength than sample Su35-100. The content of other impurities gives no explanation for the differences in strength as well.

It is remarkable that at $300^{\circ} \mathrm{C}$ and $400^{\circ} \mathrm{C}$ the flow stresses of all samples are very close. It was already mentioned that confining pressure does not influence the strength at higher temperature and also the influence of the grain size decreases. Probably the consistency of strength data is also due to the contribution of diffusional processes which are documented by the new formation of pyrite during the $400^{\circ} \mathrm{C}$-test of the Cerro de Pasco ore.

The different orientations between the compression axis and the strong c-axis maximum of the three series of the Sullivan ore seem to have little influence on the flow stresses. The order of strength of the different orientations is not the same at all temperatures, but there seems to be a tendency that the strength decreases with increasing angle between the initial c-axis maximum and the compression axis. Although sample Su82-25 has the largest strength at $25^{\circ} \mathrm{C}$ and Su8-300 and Su82-300 have nearly the same strength at $300^{\circ} \mathrm{C}$. The reasons for these irregularities cannot be explained by means of the experimental results and they may be due to experimental deviations. The mentioned order of strength can also be observed in previous deformation tests on the Sullivan ore by Niederschlag (1992) with similar orientations of the compression axis but slower strain rates between $5.9 \times 10^{-6}$ and $7.5 \times 10^{-6} \mathrm{~s}^{-1}$ at 200 , 300 , and $400^{\circ} \mathrm{C}$ (Table 5 and Figure 10 ).

Table 5 Deformation experiments on polycrystalline pyrrhotite ore from Sullivan mine, Canada (Niederschlag 1992).

\begin{tabular}{|c|c|c|c|c|c|c|c|c|}
\hline \multirow{2}{*}{$\begin{array}{l}\text { sample } \\
\text { Po00-200 }\end{array}$} & \multirow{2}{*}{$\begin{array}{l}\text { temp. } \\
{\left[{ }^{\circ} \mathrm{C}\right]} \\
200\end{array}$} & \multirow{2}{*}{$\begin{array}{c}\begin{array}{c}\text { conf. } \\
\text { press. }\end{array} \\
\text { [MPA] }\end{array}$} & \multirow{2}{*}{$\begin{array}{c}\begin{array}{c}\text { average } \\
\text { strain } \\
\text { rate } \\
{\left[s^{-1}\right]}\end{array} \\
5.9 \cdot 10^{-6}\end{array}$} & \multirow{2}{*}{$\begin{array}{c}\begin{array}{c}\text { total } \\
\text { strain }\end{array} \\
{[\%]} \\
14.1\end{array}$} & \multicolumn{2}{|c|}{$\begin{array}{c}\text { diff. } \text { stress } \\
\text { at } x \% \text { strain } \\
{[M P a]}\end{array}$} & \multicolumn{2}{|c|}{$\begin{array}{c}\text { max. diff. } \\
\text { stress } \\
\text { (at \% strain) } \\
{[M P a]}\end{array}$} \\
\hline & & & & & 408 & - & 419 & (13.7) \\
\hline Po00-300 & 300 & 300 & $6.6 \cdot 10^{-6}$ & 15.7 & 184 & 205 & 208 & (15.7) \\
\hline Po00-400 & 400 & 300 & $7.1 \cdot 10^{-6}$ & 15.8 & 39 & 36 & 40 & (11.9) \\
\hline Po30-200 & 200 & 300 & $6.0 \cdot 10^{-6}$ & 14.3 & 336 & - & 356 & (14.2) \\
\hline Po30-300 & 300 & 300 & $6.5 \cdot 10^{-6}$ & 15.6 & 140 & 162 & 165 & (15.6) \\
\hline Po30-400 & 400 & 300 & $7.0 \cdot 10^{-6}$ & 16.1 & 54 & 67 & 72 & (16.0) \\
\hline Po83-200 & 200 & 300 & $5.9 \cdot 10^{-6}$ & 14.6 & 316 & - & 317 & (9.4) \\
\hline Po83-300 & 300 & 300 & $7.5 \cdot 10^{-6}$ & 16.2 & 95 & 98 & 99 & (14.3) \\
\hline Po83-400 & 400 & 300 & $7.1 \cdot 10^{-6}$ & 16.2 & 41 & 48 & 50 & (13.9) \\
\hline
\end{tabular}

Note: The angles between compression axis and initial c-axis maximum were determined by $\mathrm{X}$-ray pole figures: $\mathrm{PoO0}=0$ degrees, $\mathrm{Po} 30=30$ degrees, $\mathrm{Po83}=83$ degrees. 


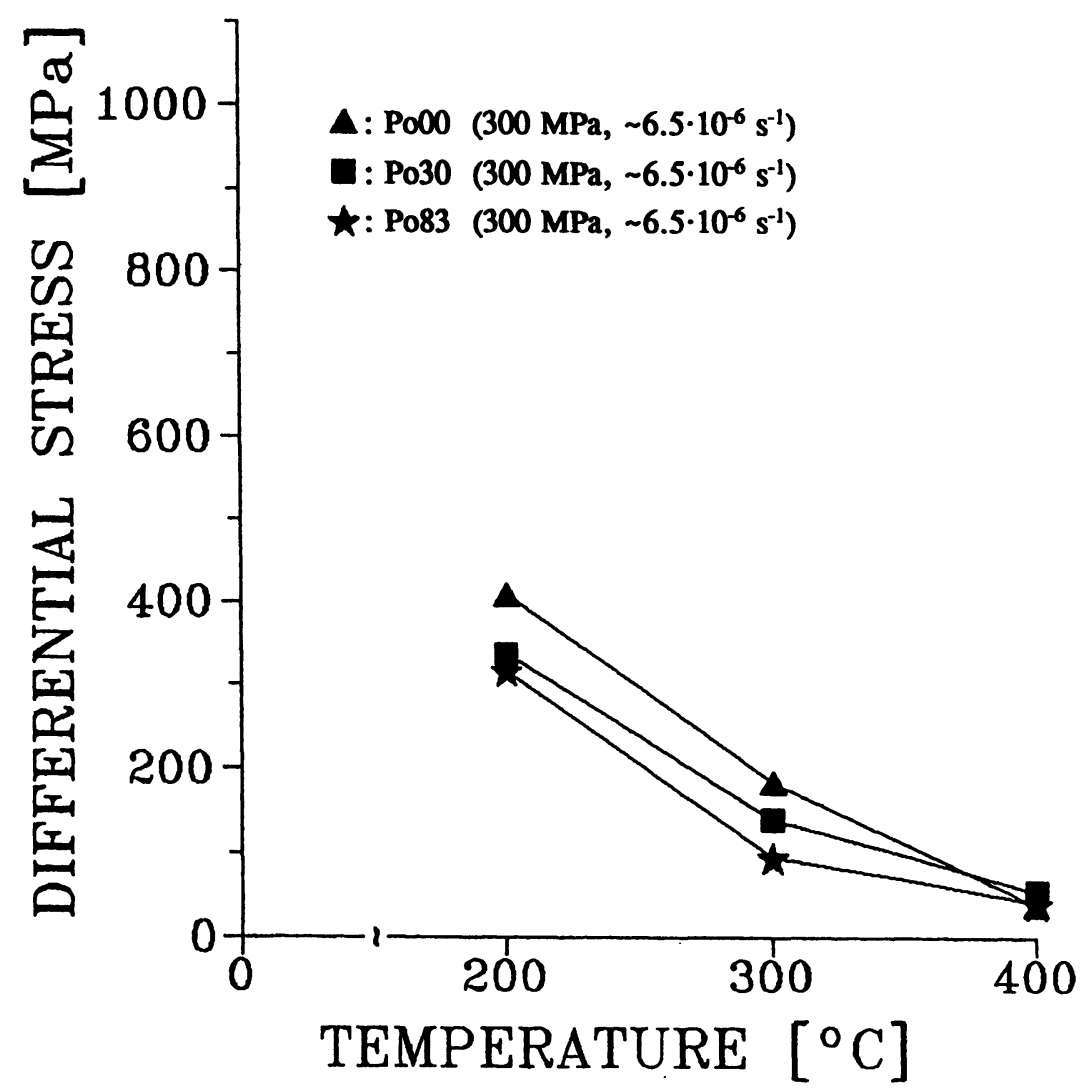

Figure 10 Pyrrhotite ore from Sullivan. Differential stress at $10 \%$ strain vs. temperature, strain rates approximately $6.5 \times 10^{-6} \mathrm{~s}^{-1}$ (Niederschlag 1992).

The experiments of Niederschlag (1992) reveal flow stresses which are as expected below the flow stresses of the faster tests. The decrease of differential stress with decreasing strain rate can also be observed from the Cerro de Pasco ore in Figure 11. Here the differential stresses at $10 \%$ strain vs. strain rate of the Cerro de Pasco ore are plotted and compared with data of tests on pyrrhotite ore from Sudbury under similar conditions by Atkinson (1975). The grain sizes of both ores are about the same. At temperatures of $200^{\circ} \mathrm{C}$ and $400^{\circ} \mathrm{C}$ the ore from Cerro de Pasco shows larger flow stresses than the Sudbury ore. Also here the reasons for the different flow stresses remain unclear. As mentioned above confining pressure is not expected to have a distinct influence above about $200^{\circ} \mathrm{C}$. The content of non-pyrrhotite minerals which varies strongly in the Cerro de Pasco samples does not allow to derive the strength as a function of impurities. A distinct influence of texture on the flow stresses of different ores is rather unlikely for the flow stress differences between the ore from Sudbury and Cerro de Pasco. Even the flow stresses of the Sullivan ore revealed only a small dependence for different orientations with respect to the strong texture (Figure 9 and Table 3). 


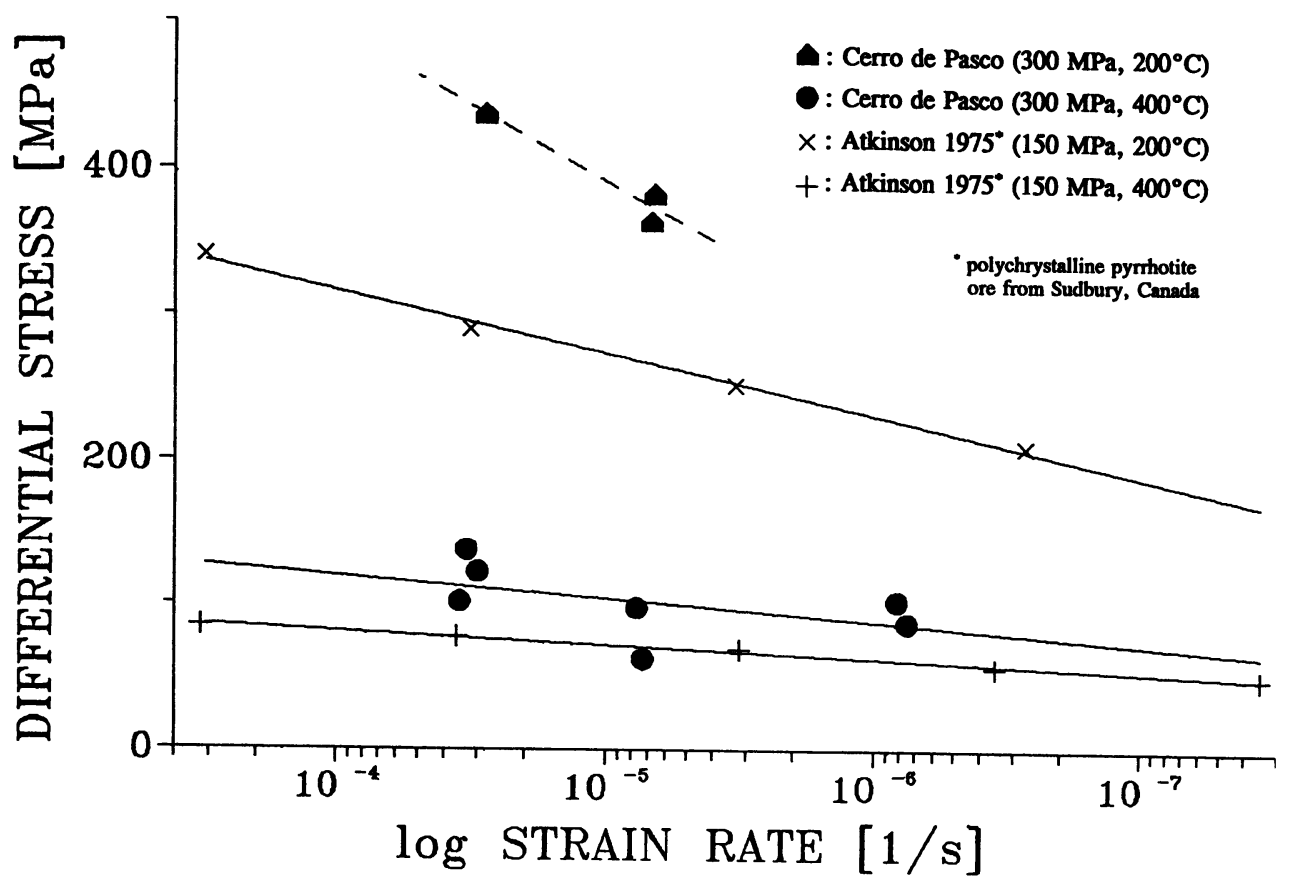

Figure 11 Pyrrhotite ore from Cerro de Pasco. Differential stress at $10 \%$ strain vs. strain rates in comparison with data at similar conditions of Atkinson (1975).

\section{CONCLUSIONS}

The experimental results show that only very special conditions with temperatures below $200^{\circ} \mathrm{C}$ and an initial texture with the c-axes nearly perpendicular to the compression axis would cause an a-axis maximum parallel to the compression axis. All other deformation conditions studied in this paper lead to the reorientation of (0001) perpendicular to the compression axis or at least a strong tendency for this development can be seen. Therefore under most conditions in the earth's crust a similar texture development should be expected. This agrees with natural occuring textures because the texture of (0001) parallel to the foliation is very common in natural metamorphic pyrrhotite ore deposits. Under natural conditions with much lower strain rates of about $10^{-14} \mathrm{~s}^{-1}$ this texture development is assumed to be even more distinct at lower total strain than in this study.

Considering the flow behaviour of pyrrhotite the present study confirmed the influence of cataclastic flow at lower temperatures and decreasing strength with lower strain rate. It was shown that a strong initial texture has only little effect on the strength of pyrrhotite. A comparison of the experimental results with those of former studies shows some differences concerning the strength of the ores from different localities at low temperatures for which an explanation was not found. Moreover it was shown that above about $300^{\circ} \mathrm{C}$ these different ores show nearly the same flow behaviour. 


\section{Acknowledgements}

The help of several persons and institutions is gratefully acknowledged. Dr. K. Walther, Dr. K. Ullemeyer, Mr. J. Heinitz and Dr. M. Betzl (Forschungszentrum Rossendorf) supported the neutron texture analyses at the diffractometer NSWR at the Joint Institute for Nuclear Research in Dubna, Russia. Dr. H.-G. Brokmeier (GKSS Forschungszentrum, Geesthacht) supported the neutron texture analyses at the diffractometer TEX-2. The staff of the Institut für Mineralogie and Lagerstättenlehre, RWTH Aachen rendered practical assistance. We thank our colleagues Dr. E. Jansen and Dr. H. Schaeben for critical comments on the manuscript. Mr. R. Hauser (Sullivan Mine, Kimberley, Canada) supplied the pyrrhotite ore from Sullivan Mine, Mr. G. del Castillo and Mr. H. Rios (Centromin, Peru) supplied the pyrrhotite ore from Cerro de Pasco. This work was financially supported by the German Bundesminister für Forschung und Technologie.

\section{References}

Arnold, R. G. (1966). Mixtures of Hexagonal and Monoclinic Pyrrhotite and the Measurement of the Metal Content of Pyrrhotite by X-Ray Diffraction. Amer. Miner., 51, 1221-1227.

Atkinson, B. K. (1975). A Preliminary Study of the Influence of Temperature and Strain Rate on the Rheology of Polycrystalline Pyrrhotite. N. Jb. Miner. Mh., 11, 483-499.

Bayer, H. and Siemes, H. (1971). Zur Interpretation von Pyrrhotin-Gefügen. Mineral. Deposita, 6, 225-244.

Böhm, H. (1987). Einführung in die Metallkunde. B.-I. Hochschultaschenbuch 196, Mannheim/Wien/ Zürich, $336 \mathrm{pp}$.

Brokmeier, H.-G. (1989). Neutron Diffraction Texture Analysis of Multi-Phase-Systems. Textures and Microstructures, 10, 325-346.

Buerger, M. J. (1928). The Plastic Deformation of Ore Minerals. Amer. Miner., 13, 35-51.

Bunge, H. J. (1989). Advantages of Neutron Diffraction in Texture Analysis. Textures and Microstructures, 10, 265-307.

Clark, B. R. and Kelly, W. C. (1973). Sulfide Deformation Studies: I. Experimental Deformation of Pyrrhotite and Sphalerite to 2,000 bars and $500^{\circ} \mathrm{C}$. Econ. Geol., 68, 332-352.

Dahms, M. (1992). The Iterative Series-Expansion Method for Quantitative Texture Analysis. Part II: Applications. J. Appl. Cryst., 25, 258-267.

Dahms, M. and Bunge H. J. (1989a). A Positivity Method for the Determination of Complete Orientation Distribution Functions. Textures and Microstructures, 10, 21-35.

Dahms, M. and Bunge, H. J. (1989b). The Iterative Series-Expansion Method for Quantitative Texture Analysis. I. General Outline. J. Appl. Cryst., 22, 439-477.

Feldmann, K. (1989). Texture Investigations by Neutron Time-of-Flight Diffraction. Textures and Microstructures, 10, 309-323.

v. Gehlen, K. (1962). Ein Pyrrhotin-Gefüge aus der Grube Bayerland bei Waldsassen. Beiträge Miner. Petro., 8, 315-322.

Gertel, H. (1992). Untersuchungen zum Texturverhalten stranggeprebter Al-Cu-Verbundwerkstoffe in Abhängigkeit vom pulvermetallurgischen Herstellungsproze $\beta$. Diss. TU Clausthal, 98 pp.

Graf, J. L. and Skinner, B. J. (1970). Strength and Deformation of Pyrite and Pyrrhotite. Econ. Geol. 65, 206-215.

Helming, K., Voitus, W. and Walther, K. (1992). Progress in Texture Investigations at the Pulsed Reactor IBR-2. Physica B, 180 \& 181, 1025-1028.

Kissin, S. A. and Scott, S. D. (1982). Phase Relations Involving Pyrrhotite below $350^{\circ}$ C. Econ. Geol., 77, $1739-1754$.

Kleinstück, K., Tobisch, J., Betzl, M., Mücklich, A., Schläfer, D., Schläfer, U. (1976). Texturuntersuchungen von Metallen mittels Neutronenbeugung. Kristall und Technik, 11, 409-429.

Kübler, L. (1985a). Deformation Mechanisms in Experimentally Deformed Single Crystals of Pyrrhotite, $\mathrm{Fe}_{(1-\mathrm{X})}$ S. Phys. Chem. Minerals, 12, 353-363.

Kübler, L. (1985b). priv. comm. in Siemes, H. and Hennig-Michaeli, C. (1985). Ore Minerals. In Preferred Orientation in Deformed Metals and Rocks: An Introduction to Modern Texture Analysis, edited by H.-R. Wenk, pp. 335-360. Orlando: Academic Press. 
Larson, L. T. (1973). Textural Study of Polycrystalline Pyrrhotite by Reflectance Measurements and X-Ray Pole Figures. Econ. Geol., 68, 671-680.

Morimoto, N., Gyobu, A., Hiromu, M. and Izawa, E. (1975a). Crystallography and Stability of Pyrrhotites. Econ. Geol., 70, 824-833.

Morimoto, N., Gyobu, A., Tsukuma, K., Koto, K. (1975b). Superstructure and Nonstoichiometry of Intermediate Pyrrhotite. Amer. Mineral., 60, 240-248.

Niederschlag, E. (1992). Experimentelle Verformung von Pyrrhotin und Bestimmung der Änderung der Regelung in Abhängigkeit von der Temperatur und Orientierung. Diplomarbeit RWTH Aachen, 79 pp., unpublished.

Niederschlag, E., Siemes, H. and Brokmeier, H.-G. (1994). Preferred Orientation of a Naturally and Experimentally Deformed Pyrrhotite Ore by X-ray and Neutron Diffraction Texture Analysis. In Proceedings of the 10th International Conference on Textures of Materials ICOTOM 10, edited by H.-J. Bunge. Materials Science Forum, 157-162, 821-826.

Niederschlag, E. (1994). Experimentelle Deformation und Neutronentexturanalyse an polykristallinem Pyrrhotin. Diss. RWTH Aachen, 105 pp.

Schmid, E. and Boas, W. (1935). Kristallplastizität. Berlin: Springer, 373 pp.

Siemes, H. and Hennig-Michaeli, C. (1985). Ore Minerals. In Preferred Orientation in Deformed Metals and Rocks: An Introduction to Modern Texture Analysis, edited by H.-R. Wenk, pp. 335-360. Orlando: Academic Press.

Traas, C., Siemes, H. and Schaeben, H. (1994). Smoothing Pole Figures Using Tensor Products of Trigonometric and Polynomial Splines. In Proceedings of the 10th International Conference on Textures of Materials ICOTOM 10, edited by H.-J. Bunge. Materials Science Forum, 157-162, 453-458.

Wenk, H.-R. (1993). Texture Analysis with TOF Neutrons. American Crystallographic Association Transactions, 29, 95-107. 